EDITORIAL

\title{
Investigations with interinstitutional participations, a significant milestone of the International SOBRADPEC Congress and Translational Research Forum
}

\section{Orlando de Castro e Silva}

Full Professor, Head of the Department of Surgery and Anatomy, Ribeirao Preto Medical School, University of Sao Paulo, Ribeirao Preto-SP, Brazil.

\section{Marina Rodrigues Garcia da Silveira}

Undergraduate Medical student, scholarship from FAPESP and Monitor of the Digestive Surgery Division, Department of Surgery and Anatomy, Ribeirao Preto Medical School, University of Sao Paulo, Ribeirao Preto-SP, Brazil.

DOI: http://dx.doi.org/10.1590/S0102-86502014001700000

When dealing with medicine in general or with surgery

The 14th version of the International SOBRADPEC Congress and Translational Research Forum deals with the topic of translational research, with important emphasis on the themes involved, which are extremely opportune and timely. The response of the Brazilian academic community exceeded expectations to such an extent that Professor Saul Goldenberg decided to publish three supplements of Acta Cirurgica Brasileira covering a total of 38 full papers enrolled in the Congress. These studies originated from practically all regions of Brazil, with a predominance of the Southeast, Northeast and South, as shown in Figure 1. We should also point out the presence of participations from Canada and France. This geographic coverage clearly shows the stage of development of clinical, experimental and especially translational research in our country, with bilateral international ramifications. The success of this congress reflects the success of Brazilian experimental surgery which, in fact is inseparable from clinical and translational research.

\section{Participation of Regions and Countries in terms of Full Papers}

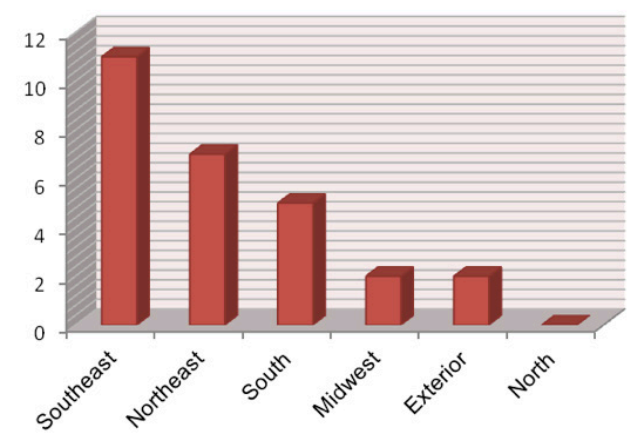

Q Quantity of Institutions

FIGURE 1 - Participation of regions and countries in terms of full papers. in particular, with translational characteristics from bench to bed and vice versa, we can see the importance of the concepts of basic research in the daily work of surgeons. Indeed, regarding the questions and ideas existing in the mind of academic surgeons and the application of knowledge to the clinical-surgical environment, the surgeon relies on his research knowledge for clinical application.

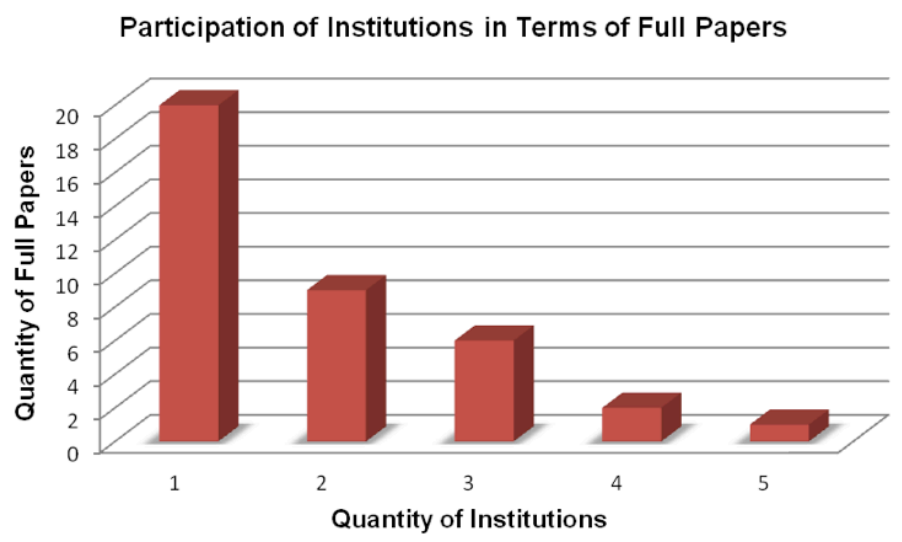

FIGURE 2 - Participation of Institutions in terms of full papers.

In the solution of tactical and technical problems during a surgical procedure, in the understanding of diseases, in the creation of basic and applied experimental models, and in the elaboration of methods from histology to molecular biology, the translational investigator threads on a blurred line between basic research and clinical application research, requiring logistic conditions that will not frustrate his expectations or the expectations of a team involved in day-to-day questions. 
As mentioned by Elias Zerhouni ${ }^{1}$, there used to be a widening gap between basic and clinical research, representing the gap existing between one modality of investigation and the other. It is necessary to have the ability to coexist or to walk on an imaginary bridge with skills in terms of the formation of groups of people with the expertise necessary for success, (Figure 3). The approximation of basic to clinical research or vice versa can occur in a rational manner by joining together laboratories, basic areas and clinical areas of different departments of the same institution or of the same university, or even of different universities. This permits the pooling of excellence in terms of human and financial resources for a better and more rational development of technology in order to favor a better solution of problems on the one hand and better functionality of the laboratories on the other.

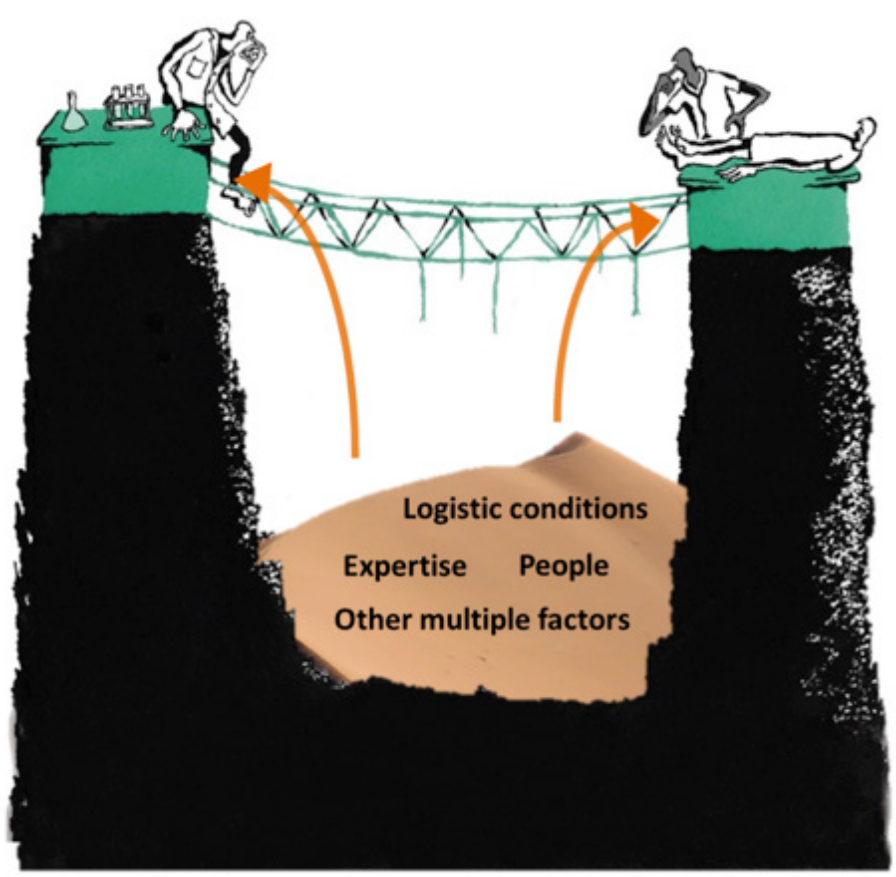

FIGURE 3 - Gap existing between clinical and basic research. Adapted and modified from Nature ${ }^{1}$

In the editorial of supplements number 1 and 2 of this trilogy $y^{2,3}$ we commented about some considerations regarding the profile of the authors of full papers published in these supplements of the XIV International SOBRADPEC Congress and Translational Research Forum and regarding the approach to translational surgery and its insertion in current medical education as a generator of medical knowledge, as well as its importance in the teaching and learning process for both students and professors of medicine.

In the current editorial, as presentation of supplement number 3, we can note the joint participation of several medical education institutions based on the origin of the authors of the 38 full papers selected for the three issues that are part of the trilogy of supplements of this Congress. Figure 2 shows that 20 studies (53\%) were performed by authors of the same institution or department. The remaining ones $(47 \%)$ were performed by authors from 2 to 5 distinct institutions, demonstrating the importance of the union of institutional forces for successful translational scientific investigation. This is a path that is being naturally followed to reduce or eliminate the existing gap or valley between the two truly rich planes, i.e., that of basic research and that of clinical research, as illustrated in Figure 3.This improves and optimizes the excellence of the investigations carried out at our medical schools as separate institutions or as institutions affiliated with universities.

Even without considering in depth the merit of the papers selected and published in these supplements, it can be clearly perceived that the interinstitutional union of forces permits the execution of studies that would probably not be easily carried out in a single institution in view of possible technical difficulties due to the frequent lack of human or logistic resources. The islands of excellence existing in our academic environment can be united in order to permit high level research. In 2013, USP formally introduced the possibility of a double teaching link in different units of the university with the main objective of increasing the capacity for both research and teaching, contributing to the improvement of institutional excellence based on the joint competence of different departments or laboratories ${ }^{1,3}$. The XIV International SOBRADPEC Congress and Translational Research Forum, presided by Professor Lydia Masako Ferreira, because of the numbers shown in Figure 1 and the essence of the papers presented in them, clearly shows the excellence of Brazilian scientific production of which Acta Cirurgica Brasileira is an exemplary vehicle from the experimental or translational viewpoint. Congratulations to Professor Lydia Masako Ferreira for the success of the Congress and to Professor Saul Goldenberg for providing the opportunity to publish the three supplements.

\section{Acknowledgements}

To Orlando Martin C. Silva and Larissa Cossalter for the graphic illustrations and for there suggestions regarding the composition of the editorials of these supplements.

\section{References}

1. Butler D. Crossing the valley of death. Nature. 2008;453:840-2.

2. Castro e Silva O, Silveira MRG. XIV International Congress SOBRADPEC. Acta Cir Bras. 2014;29(Supl 1):1-2.

3. Castro e Silva O, Cardoso NM. Translational investigation: Its essence, opportunity and merit. Medicina (Ribeirão Preto). 2012;45(4):409-10. 